\title{
Appendix Neuroendocrine Tumor by AJCC v7 Stage
}

National Cancer Institute

\section{Source}

National Cancer Institute. Appendix Neuroendocrine Tumor by A/CC v7 Stage. NCI

Thesaurus. Code C135155.

A term that refers to the staging of an appendiceal neuroendocrine tumor, following the rules of the TNM AJCC V7 classification system. 